\title{
Accident Liability with Rank Dependent Expected Utility: A comment
}

Since Calabresi (1970), law and economics scholars, when analysing liability rules, divide costs associated with accidents into primary, secondary and tertiary costs. Primary costs are associated with care effort and expected accident damages, secondary costs with risk (in the light of individual risk aversion) and tertiary costs with expenses of administering the system of deterrence and spreading risk. As is well-known, minimizing the costs separately yields very different answers. For example, minimizing tertiary costs suggests no liability at all, whereas minimizing secondary costs speaks for a form of state insurance where accident costs are spread over the entire population. The problem with both suggestions is that it would yield no incentives for potential injurers to provide adequate care. Perhaps, this explains why economists have often focussed most of their attention on primary costs at the expense of often ignoring secondary and tertiary costs altogether. As is well-known from the existing literature, in the simplest case with unilateral care, no bankruptcy risk and an exogenous activity level, the two common rules strict liability and negligence both minimize primary costs (see e.g. Shavell 1987 and the literature therein).

We know from that same literature that under standard risk aversion (i.e. introducing secondary costs using the expected utility concept) strict liability will not implement the social optimum when potential injurers minimize the sum of primary and secondary costs. Clearly, the result is not surprising: society can average risk, but in the case of strict liability the individual cannot. ${ }^{1}$ In contrast, assuming the negligence standard has been set optimally, the negligence rule fares better as seen in the following argument. If a potential injurer ignores the rule, he will behave as under strict liability, otherwise he will implement the standard. By doing so he avoids liability and, thus, all risk. $^{2}$ Applying a rationality argument immediately implies that the negligence rule weakly dominates strict liability as discussed by Eide (2006). Nothing in that logic is affected by introducing rank-dependent utility or other alternative non-expected utility concepts. As long as individuals are risk averse, the above argument and the ensuing conclusion extend, suggesting that negligence should be the preferred tort rule.

There is an additional argument for the case of Yaari's (1987) dual theory. In that theory individuals take expected value, but distort the probability weights. For example, risk averse behaviour is modelled by assuming that the individual puts too much weight on »bad « events. But of course, making such an assumption is mathematically perfectly equivalent to a situation where potential injurers are, in reality, risk neutral, but over-estimates likelihood of bad events. The latter case, however, has already been discussed in the existing literature (see e.g. Shavell 1987). It is well-

1 This is assuming individuals cannot insure themselves against liability risk. Introducing the possibility of an insurance presents an additional problem since it reduces potential injurors' care incentives. For the purpose of this note we ignore the issue.

2 Introducing a social insurance for injurees allows to spread the entire risk. 
known, that in such a situation, society should use a negligence rule for unilateral care problems. Altogether, even though an increase in realism is always useful, I am not convinced that the marginal benefit from Eide (2006) outweighs the marginal costs of introducing a new concept.

The above conclusion needs to be mitigated in two respects however. First, the above discussion completely ignores tertiary costs. Obviously, these should be larger under a negligence rule than under strict liability, since in the latter case courts are only required to verify causality, whereas under the former rule they must additionally substantiate whether the negligence standard was upheld. Second, in the law and economic literature, scholars have usually assumed that society has a clearly defined negligence standard which is taken to be known both ex-ante by potential injurers and expost by courts. Moreover, that standard is presumed to be efficient. For example, in Eide (2006) $\mathrm{x}^{*}$ is thought to correctly minimize social costs. But of course, in legal practice the issue is not as simple. In reality, in the case of accident, courts have an evident informational disadvantage with respect to injurers to assess the cost function of taking care, the exact relationship between care and the probability of accident and the true level of care expenditure undertaken. ${ }^{3}$ As is well-known from the microeconomic literature, these types of informational asymmetries require the design of complicated incentive schemes and induce significant inefficiencies. To make allowance for these problems, courts, in search of a negligence standard, often ask questions like »What can be reasonably expected in such a situation? « or »What is customarily done? « or »What was the level of scientific knowledge available to the decision maker, at the time were care was undertaken? «. ${ }^{4}$ From the point of view of potential injurers, the foregoing implies that the standard of care is fuzzy and court decision not perfectly predictable. Even under risk neutrality and in the simplest case, this may induce under- or over-production of care, thereby affecting the comparison between the two rules in favour of strict liability. Obviously, the conclusion would extend to situations where individuals have a low level of risk aversion. More generally, using the expected utility framework a comparison would seem difficult. In that respect, introducing alternative ways of capturing the notion of risk aversion may provide very useful analytical tools.

\section{References}

Calabresi, G. (1970): The Costs of Accidents, Yale University Press, New Haven and London.

Deffains, B. and D. Demougin (2006): »Customary versus Technological Advancement Tests«, BETA Discussion Paper 2006-12.

3 Eide (2006) hides the problem by assuming that the level of care is measured in terms of its expenditure $\mathrm{x}$. More generally, we could denote by $\mathrm{C}(\mathrm{x}, \mathrm{a})$ the costs of care, whereis an information known by the injuror.

4 See Deffains and Demougin (2006) for an analysis of these issues under the assumption risk neutrality. 
Eide, E. (2006): »Accident Liability with Rank Dependent Expected Utility«, this volume.

Shavell, S. (1987): Economic Analysis of Accident Law, Cambridge, MA: Harvard University Press.

Yaari, M. (1987): »The dual theory of choice under risk «, Econometrica 55, 95-116. 